Nota / Note

\title{
BIOENSAIO RÁPIDO DE DETERMINAÇÃO DA SENSIBILIDADE DA ACETOLACTATO SINTASE (ALS) A HERBICIDAS INIBIDORES ${ }^{1}$
}

\author{
Patrícia Andrea Monqueiro ${ }^{2,4 *}$; Pedro Jacob Christoffoleti ${ }^{3}$ \\ ${ }_{3}^{2}$ Pós-Graduanda do Depto. de Produção Vegetal - USP/ESALQ. \\ ${ }^{3}$ Depto. de Produção Vegetal - USP/ESALQ, C.P. 09 - CEP: 13418-900 - Piracicaba, SP. \\ ${ }^{4}$ Bolsista FAPESP. \\ *Autor correspondente <pamonque@carpa.ciagri.usp.br>
}

RESUMO: Foi avaliada a atividade da acetolactato sintase (ALS), em plantas resistentes e suscetíveis de $B$. pilosa e $A$. quitensis após a aplicação de herbicidas inibidores da ALS. O método baseia-se na utilização do ácido ciclopropanodicarboxílico (CPCA) para inibir a cetoácido reductoisomerase (KARI), enzima que catalisa a reação seguinte do acetolactato na cadeia de biossíntese dos aminoácidos valina, leucina e isoleucina, provocando assim, o acúmulo de acetolactato, que na presença de um ácido forte forma acetoína. A base para a distinção entre os biotipos resistentes e suscetíveis é a quantidade de acetoína formada, que será maior nos biotipos em que a enzima ALS não sofreu inibição, ou seja, nos biotipos resistentes. A quantificação da acetoína acumulada ocorreu através da formação de um complexo colorido vermelho, devido a reação entre acetoína, creatina e naftol, cuja densidade ótica a $530 \mathrm{~nm}$ é proporcional à concentração do acetolactato formado na reação. Sendo assim, foi desenvolvido um ensaio utilizando este método após a aplicação dos herbicidas chlorimuron-ethyl e imazethapyr nos biotipos R e $\mathrm{S}$ de Bidens pilosa, Amaranthus quitensis no estádio de dois pares de folhas. O bioensaio demonstrou que a enzima ALS dos biotipos resistentes é insensível aos herbicidas inibidores da ALS e que este tipo de bioensaio é uma forma rápida e eficaz de diferenciação entre biotipos resistentes e suscetíveis.

Palavras-chave: herbicida, resistência, acetolactato sintase, bioensaio

\section{RAPID BIOASSAY TO DETERMINE THE SENSITIVITY OF ACETOLACTATE SYNTHASE (ALS) TO INHIBITOR HERBICIDES}

\begin{abstract}
In order to compare the acetolactate synthase (ALS) activity of resistant and susceptible biotypes of Bidens pilosa and Amaranthus quitensis to ALS inhibitor herbicides, a method based on ciclopronocarboxilic acid (CPCA) to inhibit the enzyme ketoacidredutoisomerase (KARI) is used. This enzyme catalyzes the reaction after acetolactate in the biosynthesis reaction chain of the aminoacids valine, leucine and isoleucine. In the presence of a KARI inhibitor, carbon from pyruvate flows through the branched chain aminoacid biosynthetic pathway and accumulates in acetolactate, which in the presence of sulfuric acid can be converted to acetoin. The base to distinguish between the resistant and susceptible biotypes is the amount of acetoin formed, which will be much higher in the biotype where the ALS was not inhibited by the herbicide. If acetoin is mixed with naphtol and creatine the solution will develop a reddish color, so that it is possible to quantify indirectly the sensitivity of the ALS to the herbicide by the color of the solution formed. An experiment was carried out with suspected resistant biotypes of Bidens pilosa and Amaranthus quitensis using this method after spraying the plants at the two pair leaf stage with chlorimuron-ethyl and imazethapyr. The ALS of the resistant biotype has insensitivity to ALS inhibitor herbicides.
\end{abstract}

Key words: herbicide, resistance, acetolactate synthase, bioassay

\section{INTRODUÇÃO}

A resistência de plantas daninhas aos herbicidas é uma resposta evolutiva destas espécies de plantas às práticas agrícolas. Holt \& LeBaron (1990) afirmam que qualquer definição do termo resistência deve estar relacionada com a utilização do herbicida no campo, em sua dose recomendada para o controle das plantas daninhas. É importante destacar o que é resistência e o que é tolerância. No primeiro caso, a resistência pode denotar a habilidade da população de plantas, dentro de uma espécie ou de um grupo taxonômico maior, de resistir a doses maiores do que os biotipos predominantes na população selvagem podem suportar. A tolerância é a habilidade natural de algumas espécies em tolerar o produto tóxico, mesmo que estas populações nunca tenham sido expostas ao herbicida.

Atualmente, segundo Herbicide Resistance Action Commitee (HRAC), há cerca de 218 biotipos de plantas daninhas, distribuído em 145 espécies. De acordo com Heap (1999) a porcentagem de plantas resistentes no período de $1984-1997$ era de $28 \%$ resistentes aos

Parte da Dissertação de Mestrado da primeira autora apresentada à USP/ESALQ - Piracicaba, SP. 
herbicidas inibidores da ALS, $15 \%$ às triazinas, $15 \%$ aos bipiridilos, $12 \%$ as uréias e amidas, $11 \%$ aos inibidores da ACCase, $4 \%$ às dinitroanilinas e o restante distribuídos em diversas classes químicas.

O primeiro caso registrado de resistência aos herbicidas inibidores da ALS, foi relatado por Mallory-Smith et al. (1990) e Primiani et al. (1990), que identificaram biotipos resistentes de Lactuca serriola e Kochia scoparia em áreas cultivadas por trigo, nos Estados Unidos da América do Norte, apenas cinco anos após a liberação comercial do herbicida chlorsulfuron. Atualmente há problemas de resistência em cerca de 53 espécies de plantas daninhas em várias regiões do mundo, como por exemplo, Amaranthus rudis (Lovell et al., 1996a; Foes et al., 1998); Kochia scoparia (Mallory-Smith et al., 1990; Primiani et al., 1990); Galium spurium (Hall et al., 1998); Sisymbruim orientale (Boutsales \& Powles 1998); Bidens pilosa (Ponchio, (1996); Christoffoleti, et al. (1997) e Stellaria media (Kudsk et al., 1995).

Existem diversos métodos de pesquisa que estão sendo estudados com o objetivo de identificação da resistência de plantas daninhas aos herbicidas. Gerwick et al. (1993); Simpson et al. (1995) e Lovell et al. (1996b), desenvolveram um diagnóstico rápido para se detectar a resistência, através de um ensaio com a ALS no qual o ácido ciclopropanodicarboxílico (CPCA) é usado para inibir a cetoácido reductoisomerase (KARI), enzima que catalisa a reação seguinte do acetolactato na cadeia de biossíntese dos aminoácidos valina, leucina e isoleucina. $\mathrm{Na}$ ausência de inibidor da ALS, em plantas suscetíveis, o CPCA causa acúmulo de acetolactato, o produto da ALS. Quando um herbicida inibidor da ALS é aplicado juntamente com CPCA em uma planta suscetível, o acetolactato não se acumula, o contrário acontece em plantas resistentes, pois nestas plantas, a enzima ALS é insensível a ação do herbicida. Quando a quantificação do acetolactato acumulado é desejada, utiliza-se o método de Westerfeld (1945) que tem como princípio a formação de um complexo colorido na reação entre acetoína, creatina e naphtol, cuja densidade ótica a $530 \mathrm{~nm}$ é proporcional à concentração do acetolactato formado na reação.

Com o objetivo de estudar caracterização bioquímica de biotipos de Bidens pilosa e Amaranthus quitensis resistentes aos inibidores da ALS, foram realizados bioensaios com a ALS, a fim de se diagnosticar rapidamente a resistência aos herbicidas inibidores da ALS.

\section{MATERIAL E MÉTODOS}

O experimento foi realizado no Centro de Biotecnologia Agrícola (CEBTEC), da Escola Superior de Agricultura "Luiz de Queiroz", Universidade de São Paulo, Piracicaba, São Paulo.

\section{Material Vegetal}

O método, foi baseado nos trabalhos de Gerwick (1993), com algumas modificações. Sementes resistentes aos herbicidas inibidores da ALS, das plantas daninhas Bidens pilosa e Amaranthus quitensis, foram coletadas em áreas produtoras de soja dos municípios de São Gabriel do Oeste (Brasil) e de Córdoba (Argentina), respectivamente. Em São Gabriel do Oeste as sementes foram coletadas de várias plantas que sobreviveram as pulverizações com herbicidas inibidores da ALS. Estas áreas apresentam histórico de pelo menos oito anos consecutivos de uso dos herbicidas pertencentes aos grupos químicos das imidazolinonas e sulfoniluréias. As sementes de Amaranthus quitensis foram coletadas na Argentina a partir de plantas remanescentes da aplicação de herbicidas inibidores da ALS, em áreas cujo o manejo de plantas daninhas de folha larga tem sido feito por diversos anos consecutivos com herbicidas inibidores da ALS.

Outras amostras de sementes de Bidens pilosa e Amaranthus quitensis foram coletadas de áreas que nunca receberam pulverizações com os herbicidas inibidores da ALS, sendo portanto, essa população denominada de biotipos suscetíveis.

A semeadura foi realizada separadamente em bandejas com $10 \mathrm{~cm}$ de profundidade utilizando-se uma mistura de solo e matéria orgânica, as plantas se desenvolveram em casa-de-vegetação até apresentarem o segundo par de folhas verdadeiras, momento que os tratamentos foram aplicados.

\section{Tratamentos}

Foram utilizados os herbicidas inibidores da ALS pertencentes aos grupos químicos das sulfoniluréias (chlorimuron-ethyl) e das imidazolinonas (imazethapyr), e o ácido 1,1- ciclopropano-dicarboxílico (CPCA), que é um inibidor da enzima cetoácido reductoisomerase (KARI) (TABELA 1). Estas enzimas catalisam reações no processo de biossíntese dos aminoácidos valina, leucina e isoleucina. O produtos foram aplicados sobre a parte aérea das plantas com um pulverizador manual.

TABELA 1 - Tratamentos utilizados em Bidens pilosa e Amaranthus quitensis.

\begin{tabular}{|c|c|c|c|}
\hline Tratamento & Nome Comum & Nome Comercial & $\mathrm{pc}^{1} \mathrm{~mL} / \mathrm{g} / 100 \mathrm{~mL} \mathrm{H} \mathrm{H}_{2} \mathrm{O}$ \\
\hline 1 & CPCA & CPCA & 0,50 \\
\hline 3 & chlorimuron-ethyl + CPCA & Classic + CPCA & $0,20+0,50$ \\
\hline 4 & imaze thapyr + CPCA & Pivot + CPCA & $0,25+0,50$ \\
\hline 5 & testemunha & - & - \\
\hline
\end{tabular}

'Produto comercial. 
O princípio de funcionamento deste teste baseiase no fato que durante a biossíntese dos aminoácidos de cadeia ramificada, o substrato é o piruvato que na presença da enzima ALS e de cofatores, produz acetolactato. Esta reação é então paralisada pelo ácido $\mathrm{H}_{2} \mathrm{SO}_{4}$, que converte acetolactato em acetoína, que reage com creatina e naphtol produzindo um complexo de cor vermelha. Quando é aplicada a mistura do CPCA + herbicida inibidor da ALS, em plantas suscetíveis praticamente não há formação de acetoína, pois a enzima ALS é inibida pelo herbicida, portanto, não há reação colorida. Em plantas suscetíveis o composto vermelho foi produzido na presença de CPCA aplicado isoladamente, devido à inibição apenas da enzima KARI, que provoca acúmulo de acetolactato. Por outro lado, quando a mistura CPCA + herbicida inibidor da ALS é aplicada em plantas resistentes, há um acúmulo de acetolactato, devido a insensibilidade da enzima ao herbicida, havendo, portanto, a formação de um complexo colorido vermelho, devido à reação acetoína + creatina + naftol. Quanto maior a quantidade de acetoína, maior é a atividade da enzima e mais intensa é a cor desenvolvida, proporcionando valores maiores nas leituras de absorbância.

\section{Ensaio com a ALS}

O método é baseado em Gerwick et al. (1993), com algumas modificações. Após 48 horas da aplicação dos tratamentos foram colhidos os pontos de crescimento das plantas, aproximadamente $5 \mathrm{~g}$ por tratamento. $\mathrm{O}$ material vegetal foi, então, lavado em água corrente e congelado por duas horas. Após congelamento, o material vegetal foi transferido para tubos de ensaio e adicionandose água três vezes o volume do material colhido, macerando e deixando repousar por uma hora. Após o repouso, foi removida uma alíquota de $0,5 \mathrm{~mL}$ do líquido sobrenadante e transferido para novos tubos, onde foi acrescentado $0,1 \mathrm{~mL}$ de $\mathrm{H}_{2} \mathrm{SO}_{4} 5 \%$, deixando em repouso por 15 minutos, acrescentado-se $0,5 \mathrm{~mL}$ de creatina $0,5 \%$, agitação e repouso por 15 minutos, adicionando após este período, $0,5 \mathrm{~mL}$ de 1 -naphtol $5 \%$, agitação e novo repouso por 60 minutos em temperatura ambiente. Após uma hora os tubos foram agitados vigorosamente em Vortex e observada a coloração. A concentração de acetoína formada foi quantificada através de centrifugação por dez minutos em $10.000 \mathrm{~g}$ e medido absorbância em 530 nm.

\section{RESULTADOS E DISCUSSÃO}

Os dados de acumulação de acetoína pelos biotipos resistentes e suscetíveis de Bidens pilosa e Amaranthus quitensis, devido ao efeito do ácido ciclopropanodicarboxílico (CPCA), podem ser analisados na TABELAS 2 e 3 respectivamente. Os dados referemse às leituras de absorbância realizadas em espectrofotômetro à $530 \mathrm{~nm}$, subtraindo-se os valores obtidos do controle zero.

Os herbicidas inibidores da ALS chlorimuron-ethyl e imazethapyr não inibem a enzima ALS nos biotipos resistentes de ambas espécies, pois o desenvolvimento da coloração rosa ou vermelha mostra a formação de acetoína (TABELAS 2 e 3). A acetoína é indicação que houve acúmulo de acetolactato que reagiu com creatina e naphtol. Estes resultados são comprovados pelas leituras de absorbância comparativas com a testemunha no espectofotômetro. Nos biotipos suscetíveis de ambas espécies não houve formação do complexo colorido vermelho ou rosa, indicando que o acetolactato não se formou, pois a ALS, foi inibida pelos herbicidas utilizados.

Gerwick et al. (1993), utilizando CPCA, para a inibição da enzima KARI, distinguiu claramente os biotipos resistentes e suscetíveis de Xanthium strumarium ao herbicida imazaquim. Do mesmo modo, Simpson et al. (1995), constataram a acumulação de acetolactato em folhas de Glycine max (L) Merrill, Zea mays L., Amaranthus

TABELA 2 - Acumulação de acetolactato pelos biotipos resistentes e suscetíveis de Bidens pilosa.

\begin{tabular}{lllclc}
\hline Tratamento & \multicolumn{2}{c}{ Dose } & \multicolumn{2}{c}{ Biotipo Resistente } & \multicolumn{2}{c}{ Biotipo Suscetível } \\
\hline & $\left(\mathrm{mL}\right.$ ou g $\left.100 \mathrm{~mL}^{-1} \mathrm{H}_{2} \mathrm{O}\right)$ & Reação Colorida & Acetoína & Reação Colorida Acetoína \\
1 - CPCA & 0,5 & Vermelha & 2,16 & Vermelha & 1,98 \\
2 - CPCA + CHLORIMURON & $0,50+0,20$ & Vermelha & 1,81 & Marrom & 0,3 \\
3 - CPCA + IMAZETHAPYR & $0,50+0,25$ & Rosa & 1,7 & Marrom & 0,1 \\
4 - TESTEMUNHA & 0 & Marrom & 0 & Marrom & 0 \\
\hline
\end{tabular}

TABELA 3 - Acumulação de acetolactato pelos biotipos resistentes e suscetíveis de Amaranthus quitensis.

\begin{tabular}{lccccc}
\hline Tratamento & \multicolumn{2}{c}{ Dose } & \multicolumn{2}{c}{ Biotipo Resistente } & \multicolumn{2}{c}{ Biotipo Suscetível } \\
\hline & $\left(\mathrm{mL}\right.$ ou g $\left.100 \mathrm{~mL}^{-1} \mathrm{H}_{2} \mathrm{O}\right)$ & Reação Colorida & Acetoína & Reação Colorida Acetoína \\
1 - CPCA & 0,5 & Rosa & 1,57 & Rosa & 0,78 \\
2 - CPCA + CHLORIMURON & $0,50+0,20$ & Rosa & 1,53 & Marrom & 0,31 \\
3 - CPCA + IMAZETHAPYR & $0,50+0,25$ & Rosa & 1,7 & Marrom & 0,38 \\
4 - TESTEMUNHA & 0 & Marrom & 0 & Marrom & 0 \\
\hline
\end{tabular}


hybridus L., Xanthium strumarium L. e Sorghum bicolor(L) Moench, após a aplicação foliar de $766 \mathrm{~g} \mathrm{ha}^{-1}$ de CPCA, verificando também, que houve maior acúmulo de acetolactato em folhas jovens de soja.

$O$ bioensaio in vitro com a enzima ALS, através da acumulação diferencial de acetoína, é um método bastante prático e eficiente no diagnóstico de resistência de plantas daninhas aos herbicidas.

\section{CONCLUSÕES}

A aplicação do bioensaio com ALS utilizando-se o ácido CPCA que é o inibidor da KARI, constitui um método rápido de detecção da resistência causada por insensibilidade da ALS.

\section{REFERÊNCIA BIBLIOGRÁFICAS}

BOUTSALES, P.; POWLES, S.B. Seedbank characteristics of herbicide-resistant and susceptible Sisymbrium orientale. Weed Research, v.38, p.389-395, 1998.

CHRISTOFFOLETI, P.J. VICTORIA FILHO, R.; MONQUEIRO, P.A. Resistência cruzada e herbicidas alternativos de controle de biotipos de B. pilosa resistentes aos herbicidas inibidores da ALS. In: CONGRESSO BRASILEIRO DA CIÊNCIA DAS PLANTAS DANINHAS, 21., Caxambú, 1997. Resumos. Caxambú: SBPD, 1997. p64.

FOES, M.J.; LUI, L.; TRANEL, P.J.; WAX, L.M.; STOLLER, E.W. A biotype of common waterhemp (Amaranthus rudis) resistant to triazine and ALS herbicides. Weed Science, v.46, p.514-520, 1998.

GERWICK, B.C.; MIRELES, L.C.; EILERS, R.J. Rapid diagnosis of ALS/AHAS inhibitor herbicide resistant weeds. Weed Technology, v.7, p.519-524, 1993.
HALL, L.M.; STROMME, K.M.; HORSMAN, G.P. Resistance to acetolactate synthase inhibitors and quinclorac in a biotype of false cleavers (Galium spurium). Weed Science, v.46, p.390-396, 1998.

HEAP, I. International survey of herbicide resistant weeds. http://www.Weedscience.com (04 Oct.1999).

HOLT, J.; LeBARON, H.M. Significance and distribution of herbicide resistance. Weed Technology, v.4, p.141-149, 1990.

KUDSK, P.; MATHIASSEN, S.K.; COTTERMAN, J.C. Sulfonylurea resistance in Stellaria media (L) Vill. Weed Research, v.35, p.19-24, 1995.

LOVELL, S.T.; WAX, L.M.; HORAK, M.J.; PETERSON, D.E. Imidazolinone and sulfonylurea resistance in a biotype of common waterhemp (Amaranthus rudis). Weed Science, v.44, p.789-794, 1996a.

LOVELL, S.T.; WAX, L.M.; SIMPSON, D.M.; McGLAMERY, M. Using the in vivo acetolactate synthase assay for identifying herbicide-resistant weeds. Weed Technology, v.10, p.936-942, 1996b.

MALLORY-SMITH, C.A.; THILL, D.C.; DIAL, M.J. Identification of sulfonylurea herbicide resistant prickly lettuce (Lactuca seriola). Weed Technology, v.4, p.787-790, 1990.

PONCHIO, J.A. Resistência de Bidens pilosa L. Aos herbicidas inibidores da enzima acetolactato sintase. Piracicaba, 1996. 138p. Tese (Doutorado) - Escola Superior de Agricultura Luiz de Queiroz, Universidade de São Paulo.

PRIMIANI, M.M.; COTTERMAN, J.C.; SAARI, L.L. Resistance of Kochia (Kochia scoparia) to sulfonylurea and imidazolinone herbicide. Weed Technology, v.4, p.169-172, 1990.

SIMPSON, D.M.; STOLLER, E.W.; WAX, L.M. An in vivo acetolactate synthase assay. Weed Technology, v.9, p.17-22, 1995.

WESTERFELD, W.W. A colorimetric determination of blood acetoin. Journal of Biological Chemistry, v.161, p.495-502, 1945.

$\overline{\text { Recebido em 22.10.99 }}$ 